\title{
PENGARUH PELARUT ORGANIK PADA PROSES PERTUKARAN ANION DALAM PEMISAHAN URANIUM DARI LARUTAN PEB $\mathrm{U}_{3} \mathrm{Si}_{2} /$ AI PASCA IRADIASI
}

Dian Anggraini, Boybul, Yanlinastuti, Yusuf Nampira, Arif Nugroho, Rosika Kriswarini, Aslina Br Ginting

Pusat Teknologi Bahan Bakar Nuklir - BATAN

Kawasan Puspiptek, Serpong, Tangerang Selatan, 15314

e-mail : ad_09@ymail.com

(Naskah diterima: 21-06-2017, Naskah direvisi: 06-07-2017, Naskah disetujui: 07-07-2017)

\begin{abstract}
ABSTRAK
PENGARUH PELARUT ORGANIK PADA PROSES PERTUKARAN ANION DALAM PEMISAHAN URANIUM DARI LARUTAN PEB $\mathrm{U}_{3} \mathrm{Si}_{2} / \mathrm{AI}$ PASCA IRADIASI. Telah dilakukan pengembangan metode pemisahan uranium untuk meningkatkan rekoveri pemisahan uranium dalam bahan bakar nuklir pasca iradiasi. Tujuan penelitian ini adalah untuk mengetahui pengaruh pelarut organik pada proses penukar anion terhadap rekoveri uranium dari larutan bahan bakar $\mathrm{U}_{3} \mathrm{Si}_{2} / \mathrm{Al}$ pasca iradiasi potongan bagian atas. Larutan organik dalam dalam hal ini metanol terdapat dalam larutan umpan pada kolom penukar anion diharapkan dapat meningkatkan daya sorpsi resin Dowex terhadap uranium. Bahan yang digunakan sebagai umpan adalah larutan standar uranil nitrat dan supernatan larutan bahan bakar $\mathrm{U}_{3} \mathrm{Si}_{2} / \mathrm{Al}$ pasca iradiasi. Metode pemisahan uranium dilakukan dengan menggunakan kolom penukar anion dengan 2 (dua) tahapan. Kolom pertama menggunakan resin Dowex $1 \times 8-\mathrm{NO}_{3}$ dan kolom kedua dengan resin Dowex $1 \times 8-\mathrm{Cl}$. Pada kolom pertama parameter yang divariasikan adalah konsentrasi $\mathrm{HNO}_{3}$ mulai dari $1 \mathrm{M} ; 2 \mathrm{M} ; 3 \mathrm{M}$ dan $4 \mathrm{M}$, sedangkan variasi parameter pada kolom kedua adalah perbandingan volume antara $\mathrm{HCl} /$ metanol yaitu 50:50 \%; 30:70\%, 20:80\% dan 10:90\%. Hasil penelitian diperoleh rekoveri uranium maksimum sebesar $90,68 \%$ dengan komposisi media pelarut pada kolom pertama adalah $\mathrm{HNO}_{3} 3 \mathrm{M}$ dan metanol sebanyak $50 \%$ volume sedangkan pada kolom kedua digunakam media pelarut $\mathrm{HCl} 6 \mathrm{M}$ dan metanol dalam perbandingan $10 \%: 90 \%$ volume. Pada kondisi optimal diperoleh kandungan uranium dalam PEB $U_{3} \mathrm{Si}_{2} / \mathrm{Al}$ TMU $2,96 \mathrm{~g} / \mathrm{cm}^{3}$ potongan bagian atas sebesar $0,4725 \mu \mathrm{g}$.
\end{abstract}

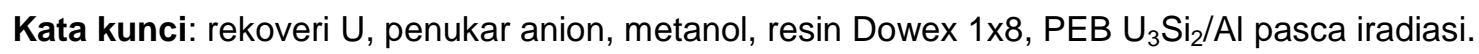




\begin{abstract}
EFFECT ORGANIC SOLVENT ON THE ANION EXCHANGE PROCESS IN URANIUM SEPARATION FROM SOLUTION OF $\mathrm{U}_{3} \mathrm{Si}_{2} /$ AI IRRADIATED FUEL PLATE. Separation method of uranium from nuclear fuel solusions was developed to improve the quality of uranium-based analysis of post-irradiation nuclear fuel. The aim of this study was to determine the effect of organic solvent on the anion exchange process on the recovery of $U$ from $U_{3} \mathrm{Si}_{2} / \mathrm{Al}$ fuel solution post-irradiated. The organic solvent, in this case methanol, contained in solvent medium in the anion exchange column may be possible to increase the resin sorption of the uranium. The materials used are standard solution of uranil nitrat and supernatant solution of Cs separation process from the fuel solution. The uranium separation method from $U_{3} \mathrm{Si}_{2} / \mathrm{Al}$ post irradiated fuel solution uses two colomns of anion exchanger with two stages. The first colomn uses Dowex 1x8-Cl Dowex resin. Parameters varied in the first colomn are $\mathrm{HNO}_{3}$ concentraions ranging from $1 \mathrm{M} ; 2 \mathrm{M} ; 3 \mathrm{M}$ and $4 \mathrm{M}$. The parameters variation in the second column is the ratio of $\mathrm{HCl} /$ methanol volume of $30: 70 \% ; 20: 80 \%$ and $10: 90 \%$. The result obtained a maximum $U$ recovery of $90,68 \%$ with feed solution composition in the first column containing $3 \% \mathrm{HNO}_{3}$ and methanol by $50 \%$ volume, while in the second column with $6 \mathrm{M} \mathrm{HCl}$ composition with methanol ini $10 \%: 90 \%$ ratio. In these conditions obtained uranium content in a solution of the middle PEB $U_{3} S_{2} / A I T M U$ $2.96 \mathrm{~g} / \mathrm{cm}^{3}$ piece of $0,4725 \mu \mathrm{g}$.
\end{abstract}

Keywords: $U$ recovery, anion exchange, methanol, Dowex $1 \times 8, U_{3} S_{2} / A l$ post-irradiation. 


\section{PENDAHULUAN}

Burn up atau derajat bakar sangat tergantung kepada spesifikasi dan jenis bahan bakar serta kondisi proses iradiasi selama di reaktor. Perbedaan parameter ini akan berpengaruh kepada komposisi kimia isotop fisil $\left({ }^{235} \mathrm{U}\right)$ dari bahan bakar pasca iradiasi. Data kuantitatif parameter diatas berguna untuk mengetahui kinerja reaktor seperti efektifitas penggunaan bahan bakar nuklir, optimasi managemen bahan bakar serta perhitungan akuntabilitas safeguard dari bahan nuklir[1]. Beberapa metode telah dikembangkan untuk menentukan burn up baik secara uji tidak merusak maupun uji merusak. Metode uji merusak secara radiokimia dilakukan untuk menentukan isotop spesifik sebagai monitor burn up seperti isotop $U$, Pu dan Nd serta Cs. Jenis isotop tersebut telah digunakan sebagai acuan untuk perhitungan burn up bahan bakar pasca iradiasi[2].

Penentuan kandungan uranium secara radiokimia untuk perhitungan burn up meliputi beberapa tahapan proses yaitu proses pelarutan, pemisahan dan pengukuran isotop dengan spektrometer alpha dan gamma. Pemisahan uranium dalam larutan bahan bakar pasca iradiasi dapat dilakukan dengan metode evaporasi, pengendapan, solvent extraction dan kolom penukar ion. Metode penukar ion lebih sering digunakan oleh para penelliti untuk melakukan pemisahan uranium baik dalam larutan bahan bakar maupun dari matrik lainnya seperti sampel geologi, limbah dan sampel lingkungan[3,4,5]. Hal ini disebabkan karena metode penukar ion memiliki beberapa keunggulan dari metode lainnya diantaranya lebih sedehana, mampu memisahkan unsur dengan konsentrasi rendah (trace element) serta limbah yang dihasilkan dalam jumlah sedikit[5]. Dalam pemisahan uranium dari larutan bahan bakar nuklir pasca iradiasi, metode penukar anion telah digunakan sebagai metode standar seperti yang tercantum dalam ASTM C1411-01[6].

Metode ASTM C1411-01 telah digunakan oleh peneliti sebelumnya untuk pemisahan uranium dari larutan pelat elemen bakar (PEB) $\mathrm{U}_{3} \mathrm{Si}_{2} / \mathrm{Al}$ dengan densitas uranium sebesar $2,96 \mathrm{gU} / \mathrm{cm}^{3}[7,8]$. Metode ini menggunakan dua kolom penukar anion yaitu kolom penukar anion dengan resin Dowex $1 \times 8-\mathrm{NO}_{3}$ dan kolom penukar anion kedua menggunakan resin Dowex $1 \times 8-\mathrm{Cl}$. Kolom penukar anion pertama digunakan untuk memisahkan uranium dari unsur bermassa berat lainnya seperti Pu dan pada kolom kedua untuk memisahkan uranium dari unsur - unsur yang dihasilkan dari hasil reaksi fisi isotop ${ }^{235} \mathrm{U}$ dalam reaktor. Rekoveri pemisahan uranium yang telah diperoleh dengan menggunakan metode ini hanya sebesar $68,2 \%[8]$. Besaran rekoveri tersebut dipandang masih rendah bila dibandingkan dengan rekoveri pemisahan cesium dalam bahan bakar pasca iradiasi yang telah diperoleh pada penelitian sebelumnya sebesar 99,4\%[8].

Dalam usaha untuk meningkatkan rekoveri tersebut, diperlukan upaya pengembangan metode analisis dalam rangka meningkatkan mutu hasil analisis. Salah satu cara yang dilakukan adalah meningkatan daya adsorpsi resin Dowex terhadap ion kompleks metal. Daya adsorpsi resin Dowex pada proses kolom penukar anion sangat dipengaruhi oleh beberapa faktor diantaranya adalah komposisi media pelarut atau jenis larutan umpan. Penelilti sebelumya telah mempelajari pertukaran ion kompleks dalam kolom penukar anion dan mendapatkan bahwa keberadaan pelarut organik dalam kolom dapat meningkatkan daya adsorpsi resin. Hal ini telah dibuktikan oleh peneliti sebelumnya yang menggunakan larutan metanol $50 \%$ volume sebagai pelarut dalam pemisahan uranium dan thorium[3]. Pemisahan uranium dalam batuan juga telah dilakukan dengan 
menggunakan larutan campuran organik dan diperoleh kandungan uranium lebih besar. Pada pemisahan unsur-unsur lantanida dengan menggunakan metanol sebagai pelarut organik, telah dibuktikan adanya peningkatan daya adsorpsi ion lantanida ke dalam resin[9]. Fenomena ini disebabkan sifat fisik dari pelarut oganik seperti viskositas, polaritas dan konstanta dieletrik dapat mengakibatkan perubahan sifat pada larutan umpan kolom[10]. Perubahan sifat tersebut mengakibatkan interaksi ion metal dengan ligan resin semakin meningkat. Hal ini menjadikan dasar atau latar belakang untuk melakukan penelitian agar dapat meningkatkan rekoveri pemisahan uranium dalambahan bakar $\mathrm{U}_{3} \mathrm{Si}_{2} / \mathrm{Al}$ pasca iradiasi, sehingga data perhitungan burn up dapat lebih akurat.

\section{METODOLOGI}

Bahan penelitian adalah larutan standar $\mathrm{U}_{3} \mathrm{O}_{8}$ yang telah dilarutkan menjadi uranil nitrat dan larutansupernatan PEB $\mathrm{U}_{3} \mathrm{Si}_{2} / \mathrm{Al}$ pasca iradiasi. Proses pemisaan uranium dilakukan dengan 2 tahap. Tahap pertama dilakukan menggunakan kolom penukar anion dengan resin Dowex $1 \times 8-\mathrm{NO}_{3}$ dan pada tahap kedua dilakukan pada kolom penukar anion dengan resin Dowex $1 \times 8-\mathrm{Cl}$. Jumlah resin Dowex $1 \times 8$ yang digunakan pada kolom pertama dan kolom kedua masing- masing sebanyak 1,2 gram.

Peralatan yang digunakan adalah satu unit kolom penukar anion dibuat dari bahan gelas dengan diameter $=0,9 \mathrm{~cm}$ dan tinggi $10 \mathrm{~cm}$, sel elektrodeposisi dan planset stainless steel (SS) dengan diameter $1 \mathrm{~cm}$. Poses elektrodeposisi dilakukan untuk preparasi sampel sumber alpha berupa deposit uranium pada permukaan planset SS. Untuk mengetahui kandungan isotop uranium, planset SS selanjutnya dianalisa menggunakan spekrtrometer alpha yang telah dikalibrasi menggunakan standar AMR 43 dari NIST (National Institute of Standars
Technology). Hasil kalibrasi digunakan untuk mengetahui efisiensi detektor serta kesesuaian antara nomor kanal dengan energi isotop pemancar alpha. Efisiensi detektor digunakan untuk perhitungan uranium secara kuantitatif.

Rekoveri pemisahan uranium dilakukan dengan pemanasan larutan uranil nitrat sebanyak 500 uL sampai kisat. Larutan tersebut dikenakan proses oksidasi dan reduksi menggunakan larutan $\mathrm{HNO}_{3}$ sebanyak $3 \mathrm{~mL}$ dan $\mathrm{FeSO}_{4} 0,1 \mathrm{M}$. Larutan diaduk dan ditambah larutan $\mathrm{HNO}_{3}$ pekat sehingga menjadi larutan standar dalam $\mathrm{HNO}_{3} 8 \mathrm{M}$. Sementara itu, untuk mendapatkan larutan standar dengan variasi konsentrasi $\mathrm{HNO}_{3} 1 \mathrm{M}$; $2 \mathrm{M}$; $3 \mathrm{M}$ dan $4 \mathrm{M}$ dilakukan pengenceran menggunakan ABM. Larutan standar dengan variasi konsentrasi $\mathrm{HNO}_{3}$, kemudian ditambah metanol dengan perbandingan volume $50 \%: 50 \%$. Larutan standar yang telah bercampur dengan metanol digunakan sebagai umpan pada kolom pertama. Sebelum larutan standar dimasukkan ke dalam kolom terlebih dahulu resin Dowex dikondisikan dengan menggunakan $20 \mathrm{~mL}$ larutan campuran $\left(\mathrm{HNO}_{3}\right.$ +metanol) dengan variasi konsentrasi nitrat sesuai dengan kondisi larutan standar. Efluent uranium yang diperoleh dari kolom pertama kemudian dipanaskan sampai kisat dan ditambahkan larutan campuran $(\mathrm{HCl}+$ metanol) dengan perbandingan $\mathrm{HCl} /$ metanol sebesar $20 / 80 \%$. Proses pada kolom kedua, uranium akan terikat dengan resin, kemudian uranium dielusi dengan larutan $\mathrm{HNO}_{3} \quad 0,35 \mathrm{M}$ sebanyak $15 \mathrm{~mL}$. Hasil elusi uranium (efluen $\mathrm{U}$ ) kemudian dikisatkan dan dikenakan proses elektrodeposisi[11] untuk selanjutnya dapat dianalisis kuantitatif menggunakan spektrometer alpha. Rekoveri pemisahan uranium dihitung dengan cara membandingkan kandungan uranium mula mula dengan kandungan uranium setelah melalui proses kolom pertukaran anion.

Konsentrasi $\mathrm{HNO}_{3}$ optimum pada kolom pertama, selanjutnya digunakan untuk 
pemisahan uranium dengan variasi perbandingan volume $\mathrm{HCl}$ dan metanol pada kolom kedua sebesar 20:80 \%; 30:70 \% dan $10: 90 \%$. Langkah kerja yang sama dilakukan untuk penentuan rekoveri uranium variasi konsentrasi nitrat, sehingga diperoleh perbandingan volume $\mathrm{HCl}$ dan metanol yang optimal untuk digunakan sebagai pelarut organik pada kolom kedua.

Parameter optimal yang diperoleh pada kolom pertama dan kedua, selanjutnya digunakan untuk proses pemisahan uranium dalam supernatan PEB $U_{3} \mathrm{Si}_{2} / \mathrm{Al}$ pasca iradiasi. Supernatan $\mathrm{PEB} \mathrm{U}_{3} \mathrm{Si}_{2} / \mathrm{Al}$ sebanyak $500 \mu \mathrm{L}$ diuapkan sampai kisat, kemudian ditambah larutan $\mathrm{HNO}_{3} 8 \mathrm{~N}$ sebanyak $5 \mathrm{~mL}$ dan dikisatkan kembali. Larutan yang telah kisat selanjutnya dikenakan proses penukar anion dengan resin Dowex $1 \times 8-\mathrm{NO}_{3}$ dan resin Dowex $1 \times 8-\mathrm{Cl}$ menggunakan parameter optimum yang telah diperoleh sebelumnya. Kandungan uranium dalam supernatan PEB $\mathrm{U}_{3} \mathrm{Si}_{2} / \mathrm{Al}$ selanjutnya dianalisis dengan spektrometer alpha.

\section{HASIL DAN PEMBAHASAN}

\section{a. Penentuan optimasi parameter}

Hasil pengukuran efluen $U$ yang diperoleh dari kolom pertama dengan umpan campuran larutan standar uranil nitrat dan metanol dengan variasi konsentrasi $\mathrm{HNO}_{3} 1 \mathrm{M} ; 2 \mathrm{M} ; 3 \mathrm{M}$ dan 4M tercantum pada Tabel 1.

Tabel 1. Data kandungan isotop $U$ pada kolom pertama

\begin{tabular}{|c|c|c|c|c|c|}
\hline \multirow{2}{*}{ KonsentrasiHNO } & \multirow{4}{*}{ Kandungan isotop $U(\mu \mathrm{M})$} & \multirow{2}{*}{ Ratio isotop ${ }^{234} \mathrm{U} /{ }^{238} \mathrm{U}$} \\
\cline { 2 - 5 } & ${ }^{238} \mathrm{U}$ & ${ }^{235} \mathrm{U}$ & ${ }^{236} \mathrm{U}$ & ${ }^{234} \mathrm{U}$ & \\
\hline 1 & 31,986 & 8,504 & 0,084 & 0,049 & 0,0015 \\
\hline 2 & 19,925 & 6,986 & 0,117 & 0,033 & 0,0016 \\
\hline 3 & 31,880 & 9,686 & 0,096 & 0,051 & 0,0016 \\
\hline 4 & 28,572 & 8,171 & 0,076 & 0,040 & 0,0016 \\
\hline
\end{tabular}

Tabel 1 menunjukkan bahwa parameter optimal untuk pemisahan $U$ pada kolom pertama terjadi pada penggunaan $\mathrm{HNO}_{3}$ dengan konsentrasi $3 \mathrm{M}$. Hal ini ditunjukkan oleh kandungan ${ }^{235} \mathrm{U} ;{ }^{236} \mathrm{U}$ dan ${ }^{234} \mathrm{U}$ diperoleh paling besar pada penggunaan $\mathrm{HNO}_{3}$ dengan konsentrasi $3 \mathrm{M}$ yaitu sebesar 9,686 $\mu \mathrm{g} ; 0,096 \mu \mathrm{g} ; 0,051 \mu \mathrm{g}$.

Pemilihan parameter optimal penggunaan $\mathrm{HNO} 3$ pada konsentrasi $3 \mathrm{M}$ dalam pemisahan $U$ didukung oleh perhitungan ratio isotop ${ }^{234} \mathrm{U} /{ }^{238} \mathrm{U}$. Kandungan uranium yang paling besar dalam larutan uranil nitrat maupun dalam bahan bakar pasca iradiasi adalah isotop ${ }^{234} U$ dan ${ }^{238} U$ dan dalam kondisi stabil seperti yang ditunjukkan pada Gambar 1.

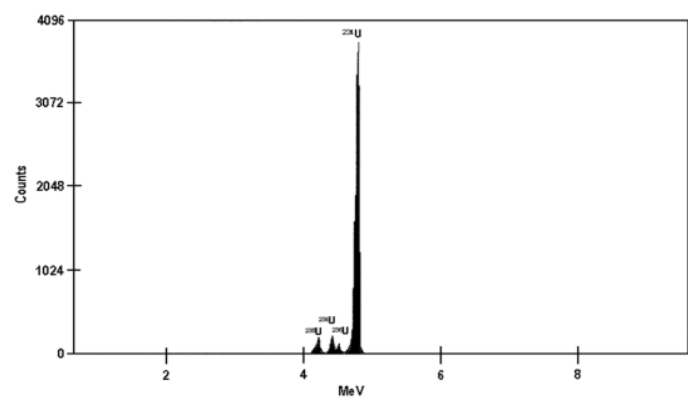

Gambar 1. Spektrum isotop $U\left({ }^{238} \mathrm{U} ;{ }^{235} \mathrm{U}\right.$; ${ }^{236} U$ dan ${ }^{234} U$ ) dalam larutan standar uranil nitrat

Gambar 1 menunjukkan bahwa dalam standar uranil nitrat kandungan ${ }^{234} \mathrm{U}$ dan ${ }^{238} \mathrm{U}$ diperoleh lebih besar dari pada kandungan ${ }^{235} \mathrm{U}$ dan ${ }^{236} \mathrm{U}$, sehingga umumnya ratio ${ }^{234} \mathrm{U} /{ }^{238} \mathrm{U}$ digunakan sebagai indikator keberhasilan pemisahan maupun penyimpangan pemisahan uranium secara radiokimia. Tabel 1 menunjukkan bahwa ratio isotop ${ }^{234} \mathrm{U} /{ }^{238} \mathrm{U}$ untuk $\mathrm{HNO}_{3}$ dengan 
konsentrasi $1 \mathrm{M}$ diperoleh sebesar 0,0015 dan ratio isotop ${ }^{234} \mathrm{U} /{ }^{238} \mathrm{U}$ pada konsentrasi $\mathrm{HNO}_{3} 2 \mathrm{M} ; 3 \mathrm{M}$ dan $4 \mathrm{M}$ masing-masing sebesar 0,0016 . Ratio ${ }^{234} U /{ }^{238} U$ pada konsentrasi $\mathrm{HNO}_{3} \quad 1 \mathrm{M}$ mempunyai perbedaan sekitar $7 \%$ dengan ratio ${ }^{234} \mathrm{U} /{ }^{238} \mathrm{U}$ pada konsentrasi $\mathrm{HNO}_{3} 2 \mathrm{M}$; $3 \mathrm{M}$ dan $4 \mathrm{M}$. Data ini menunjukkan bahwa penyimpangan metode pemisahah $U$ pada kolom pertama diperoleh sebesar $7 \%$. Secara statistik, penyimpangan sebesar $7 \%$ dapat diterima karena besar penyimpangan lebih kecil dari $10 \%$ (persyaratan).

Selain parameter penggunaan pelarut $\mathrm{HNO}_{3}$ yang optimal, ditentukan juga parameter optimal rekoveri pemisahan uranium dalam larutan uranil nitrat seperti yang terlihat pada Tabel 2 .

Tabel 2. Rekoveri uranium pada konsentrasi $\mathrm{HNO}_{3}$ dan metanol $50 \%$ volume

\begin{tabular}{|c|c|c|c|}
\hline \multirow{2}{*}{$\begin{array}{c}\text { Konsentrasi } \mathrm{HNO}_{3}, \\
(\mathrm{M})\end{array}$} & \multicolumn{2}{|c|}{ Kandungan uranium $(\mu \mathrm{g})$} & $\begin{array}{c}\text { Rekoveri pemisahan } \mathrm{U} \\
(\%)\end{array}$ \\
\cline { 2 - 3 } & Sebelum pemisahan & Setelah pemisahan & 49,66 \\
\hline 1 & 50 & 24,832 & 32,47 \\
\hline 2 & 50 & 16,237 & 83,83 \\
\hline 3 & 50 & 41,715 & 73,73 \\
\hline 4 & 50 & 36,867 & \\
\hline
\end{tabular}

Tabel 2 menunjukkan bahwa nilai rekoveri uranium yang diperoleh dari larutan umpan pada kolom penukar anion dengan resin Dowex- $\mathrm{NO}_{3}$ mencapai maksimum $83,83 \%$ pada konsentrasi $\mathrm{HNO}_{3} 3 \mathrm{M}$ dan metanol $50 \%$ volume. Besaran rekoveri ini mengalami peningkatan dari $68,21 \%$ pada penelitian sebelumnya (hanya menggunakan pelarut $\mathrm{HNO}_{3}$ dengan konsentrasi $8 \mathrm{M})$ menjadi rekoveri sebesar $83,83 \%$ dengan menggunakan pelarut $\mathrm{HNO}_{3}$ dan methanol pada perbandingan volume
$50: 50 \%$. Fenomena ini menunjukkan bahwa penggunaan pelarut yang berbeda (pelarut organik) dapat meningkatkan daya adsorpsi resin terhadap kompleks ion uranium.

Efluen uranium yang keluar dari kolom pertama, digunakan sebagai umpan pada kolom kedua. Pemisahan uranium pada kolom kedua dilakukan dengan variasi perbandingan $\mathrm{HCl} 6 \mathrm{M}$ dengan metanol dan nilai rekoveri yang diperoleh tercantum pada Tabel 2.

Tabel 2. Data rekoveri U dengan pelarutan campuran $(\mathrm{HCl}$ dan metanol)

\begin{tabular}{|c|c|c|c|}
\hline $\begin{array}{c}\text { Perbandingan } \mathrm{HCl}: \text { metanol } \\
(\% \text { volume })\end{array}$ & \multicolumn{2}{|c|}{ Kandungan $\mathrm{U}(\mu \mathrm{gg})$} & $\begin{array}{c}\text { Rekoveri pemisahan } \mathrm{U} \\
\text { (\%) }\end{array}$ \\
\cline { 2 - 3 } & $\begin{array}{c}\text { Sebelum } \\
\text { pemisahan }\end{array}$ & $\begin{array}{c}\text { Sesudah } \\
\text { pemisahan }\end{array}$ & \\
\hline $30: 70$ & 50 & 20,17 & 40,35 \\
\hline $20: 80$ & 50 & 44,36 & 88,71 \\
\hline $10: 90$ & 50 & 45,34 & 90,68 \\
\hline
\end{tabular}

Tabel 2 menunjukkan bahwa rekoveri pemisahan $U$ meningkat dengan naiknya jumlah metanol dalam media pelarut. Pemisahan uranium pada Tabel 2 menunjukkan bahwa kondisi atau parameter optimum tercapai pada perbandingan $\mathrm{HCl}$ dengan metanol pada 10:90 \% volume dengan rekoveri sebesar $90,68 \%$.
Metanol merupakan pelarut organik yang banyak digunakan dalam proses penukar ion untuk menaikkan daya adsorpsi resin terhadap kompleks ion logam. Pada pustaka menyatakan bahwa keberadaan metanol dalam media pelarut menyebabkan beberapa sifat fisis media pelarut berubah seperti polaritas, kontanta dielektrik, 
viskositas dan titik didih[11]. Hal ini disebabkan karena adanya perbedaan sifat fisik pelarut (air) dan metanol seperti yang dapat dilihat pada Tabel 3.

Tabel 3 .Sifat fisis air dan metanol

\begin{tabular}{|c|c|c|}
\hline Sifat fisik & Air & Metanol \\
\hline Polaritas & 74 & 34 \\
\hline Konstanta dielektrik & 78,36 & 32,6 \\
\hline Viskositas $(\mathrm{mPas})$ & 0,895 & 0,55 \\
\hline Titik didih $\left(0^{\circ} \mathrm{C}\right)$ & 100 & 64,80 \\
\hline Densitas $\left(\mathrm{g} / \mathrm{cm}^{3}\right)$ & 0,997 & 0,79 \\
\hline
\end{tabular}

Polaritas pelarut merupakan faktor yang berpengaruh pada pengembangan resin (swelling resin), semakin polar media pelarut mengakibatkan swelling resin semakin besar. Pada kondisi ini resin akan mengandung air berlebih sehingga resin akan mudah rusak. Adanya metanol dalam media pelarut menurunkan polaritas pelarut sehingga swelling resin akan lebih rendah jika dibanding dengan pelarut tanpa metanol. Penurunan swelling resin mengakibatkan daya adsorpsi semakin meningkat. Fenomena ini sesuai dengan pernyataan yang terdapat dalam pustaka yang menyatakan bahwa berkurangnya swelling resin sama seperti peningkatan crosslinkage resin[12]. Bertambahnya crosslinkage dalam resin mengakibatkan porositas menurun sehingga hidrasi berkurang. Hal ini menyebabkab interaksi ion uranium kompleks dengan ligan resin menjadi meningkat. Jumlah pertambahan crosslikage atau penurunan swelling resin mempunyai batasan maksimum. Bila melebihi batasan maksimum jumlah pori semakin sedikit sehingga kapasitas tukar anion menjadi berkurang. Dari hasil penelitian ini diperoleh parameter optimum tercapai pada perbandingan $\mathrm{HCl}$ dengan metanol pada10:90 \% volume.

Tabel 3 menunjukkan bahwa konstanta dielektrik menurun dengan adanya metanol dalam media pelarut. Beberapa peneliti sebelumnya mendapatkan bahwa penurunan konstanta media pelarut dapat meningkatkan daya adsorpsi resin terhadap U. Hal ini terjadi dimungkinkan karena media pelarut dengan konstanta dielektrik rendah akan menekan proses disosiasi senyawa kompleks $\left(\mathrm{UO}_{2} \mathrm{Cl}_{2}\right)$ sehingga $\mathrm{UO}_{2} \mathrm{Cl}_{2}$ yang tidak terurai langsung diserap oleh resin dan menghasilkan senyawa dengan struktur (Rs $\left.\cup_{2}\right)\left(\cup_{2} \mathrm{Cl}\right)$ [12] Menurunnya nilai polaritas larutan menyebabkan konstanta dieletrik larutan juga menjadi menurun. Fenomena ini didukung oleh hasil penelitian mengenai efek konstanta dielektrik dalam sistem yang berkaitan dengan data ekstraksi uranium. Parameter penelitian dilakukan pada $99 \%$ alkohol dan $1 \% \mathrm{HCl} 6 \mathrm{M}$ dengan variasi konsentrasi alkohol dan diperoleh koefisien distribusi (Kd) dari 0 pada media pelarut dengan konstanta dieletrik sebesar 88 dalam media air menjadi $1.10^{5}$ pada media pelarut dengan konstanta dielektrik sebesar 3 dalam media dioxane[12,13].

Sifat fisis lain yang berubah dengan adanya metanol adalah viskositas dan titik didih. Perubahan kedua sifat ini berpengaruh pada kecepatan proses pemisahan dan kemudahan dalam proses preparasi pembuatan sumber alpha $U$ dalam dalam planset. Viskositas media pelarut menjadi lebih rendah mengakibatkan waktu tinggal akan lebih lama sehingga proses dapat lebih cepat dengan menaikkan kecepatan alir media pelarut. Pada proses pembuatan sumber alpha $U$ diperlukan proses penguapan dari larutan elusi U. Titik didih media pelarut yang lebih rendah dapat memprcepat proses penguapan dan menghasilkan residu minimum.

\section{Pemisahan $U$ dalam supernatan PEB $\mathrm{U}_{3} \mathrm{Si}_{2} / \mathrm{Al}$}

Pengukuran kandungan uranium dalam supernatan PEB $U_{3} \mathrm{Si}_{2} / \mathrm{Al}$ dilakukan sebelum dan sesudah pemisahan menggunakan spektrometer alpha. Spektrum isotop supernatan sebelum 
dilakukan proses pemisahan uranium ditunjukkan pada Gambar 2.

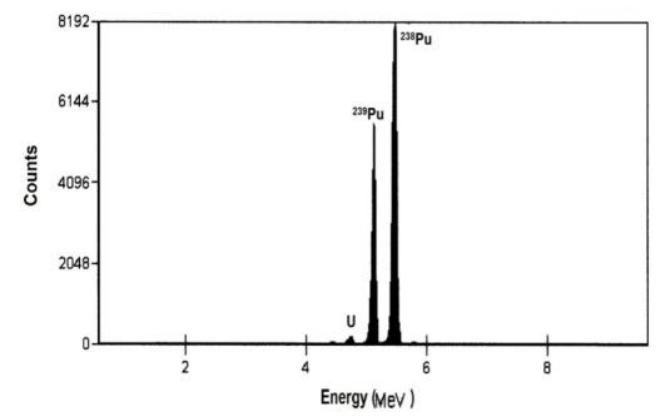

Gambar 2. Spektrum isotop $U$ sebelum proses pemisahan

Gambar 2 menunjukkan bahwa spektrum isotop $U\left({ }^{238} U ;{ }^{235} U ; U^{236}\right.$ dan $\left.{ }^{234} U\right)$ terlihat sangat kecil dan menyatu satu dengan lainnya, sedangkan spektrum isotop $\mathrm{Pu}\left({ }^{238} \mathrm{Pu}\right.$ dan $\left.{ }^{239} \mathrm{Pu}\right)$ terlihat sangat tinggi dan jelas terpisah. Hal ini yang menjadikan pertimbangan untuk melakukan proses pemisahan $\mathrm{U}$ dan $\mathrm{Pu}$ dalam larutan supernatan agar spektrum $U$ terlihat lebih jelas dan dapat ditentukan secara kuantitatif dengan akurat.

Pemisahan uranium dalam supernatan PEB $\mathrm{U}_{3} \mathrm{Si}_{2} / \mathrm{Al}$ dilakukan dengan menggunakan parameter optimum (diperoleh dari hasil analisis terhadap standar uranil nitrat). Pada kolom pertama digunakan media pelarut $\mathrm{HNO}_{3}$ dengan konsentrasi 3M dan metanol $50 \%$ volume, sedangkan pada kolom kedua digunakan media pelarut adalah $\mathrm{HCl} 6 \mathrm{M}$ dan metanol dengan perbandingan 10:90\% volume. Hasil pemisahan diperoleh kandungan uranium seperti yang tercantum pada Tabel 4.

Tabel 4. Kandungan isotop uranium dalam supernatant PEB $\mathrm{U}_{3} \mathrm{Si}_{2} / \mathrm{Al}$

\begin{tabular}{|c|c|}
\hline Isotop $U$ & Berat $(\mu \mathrm{g})$ \\
\hline${ }^{238} U$ & 0,3852 \\
\hline${ }^{235} U$ & 0,0804 \\
\hline${ }^{236} U$ & 0,0061 \\
\hline${ }^{234} U$ & 0,0008 \\
\hline
\end{tabular}

Berdasarkan Tabel 4 diketahui jumlah kandungan uranium masing masing untuk isotop ${ }^{238} \mathrm{U} ;{ }^{235} \mathrm{U} ;{ }^{236} \mathrm{U}$ dan ${ }^{234} \mathrm{U}$. Besar kandungan uranium dalam supernatan PEB $\mathrm{U}_{3} \mathrm{Si}_{2} / \mathrm{Al}$ diperoleh dari luasan spektrum isotop uranium hasil pengukuran menggunakan spektrometer alpha seperti yang ditunjukkan pada Gambar 3.

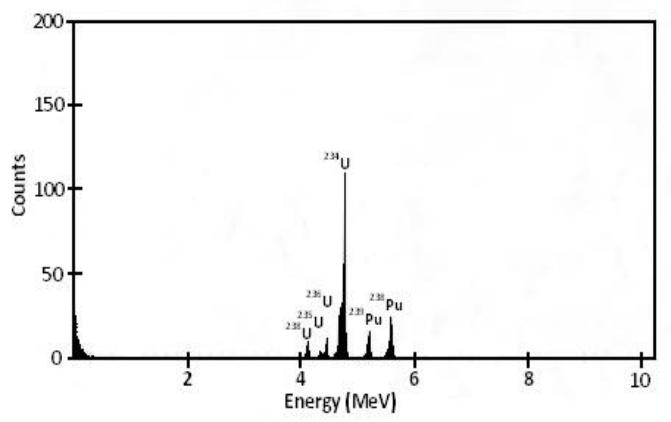

Gambar 3. Spektrum isotop $U$ setelah proses pemisahan

Gambar 3 menunjukkan bahwa setelah dilakukan pemisahan diperoleh spektrum dari masing-masing isotop $U$ maupun $\mathrm{Pu}$ telah terpisah dengan baik, sehingga setiap isotop dapat dievaluasi dan dianalisis secara kuantitatif dengan mudah. Bila dibandingkan spektrum U pada Gambar 2 dengan spektrum $U$ yang ada pada Gambar 3, maka proses pemisahan $U$ dengan metode kolom penukar anion menggunakan metanol sebagai pelarut organik telah menghasilkan spektrum U dengan resolusi lebih baik.

\section{SIMPULAN}

Penggunaan media pelarut organik sangat berpengaruh dalam pemisahan uranium. Pemisahan uranium dalam supernatan PEB $\mathrm{U}_{3} \mathrm{Si}_{2} / \mathrm{Al}$ pasca iradiasi menggunakan Dowex $1 \times 8-\mathrm{NO}_{3}$ dengan media pelarut $\mathrm{HNO}_{3} 3 \mathrm{M}$ dan metanol $50 \%$ volume pada kolom pertama dan penggunaan resin Dowex $1 \times 8-\mathrm{Cl}$ dengan perbandingan $\mathrm{HCl} 6 \mathrm{M}$ dan metanol sebesar 10\%: $90 \%$ pada kolom kedua dapat meningkatkan rekoveri pemisahan uranium. 
Rekoveri pemisahan uranium menggunakan resin Dowex 1x8 tanpa methanol telah diperoleh sebesar 68,21\% (penelitian sebelumnya). Sementara itu, penggunaan methanol sebagai media organik dapat meningkatkan rekoveri pemisahan uranium menjadi 90,68\%. Pada kondisi parameter optimal diatas diperoleh kandungan uranium total dalam PEB $\mathrm{U}_{3} \mathrm{Si}_{2} / \mathrm{Al} \mathrm{TMU} 2,96 \mathrm{~g} / \mathrm{cm}^{3}$ pasca iradiasi potongan bagian atas sebesar dengan berat $0,4275 \mu \mathrm{g}$.

\section{UCAPAN TERIMAKASIH}

Terimakasih disampaikan kepada Ka. PTBBN dan Ka. BUR yang telah meyediakan dana DIPA, rekan rekan kelompok Fisikokimia dan kepada semua pihak yang telah membantu pelaksanaan penelitian ini, sehingga penulisan makalah ini dapat terwujud penulisan.

\section{DAFTAR PUSTAKA}

[1] J. S. Kim, Y. S. Jeon, S. D. Park, S. H. Han, J. G. Kim, "Burnup Determination of high burnup and dry processed fuels based on isotope dilution mass spectrometric measurements", Journal of Nuclear Science and Technology, vol. 44, no. 7, pp. 1015-1023, 2007.

[2] R. R. Heinrich, R. J. Popek, D. L, Bower, "Uranium and Plutonium Determinations for Evaluation of High Burnup Fuel Ferformance", Analytical Chemistry Laboratory, 1985.

[3] F. Monroy-Guzman, "Isolation of Uranium By Anionic Exchange Resin", Journal Chemical Engineering, vol.10,pp. 90-95, 2016.

[4] S.K. Jung, S.J. Young, D.P. Soon, K.H. Yeong, S. Kyuseok, "Analysis of high burnup pressurized water reactor fuel using uranium, plutonium, neodymium, and cesium isotope correlations with burnup," Nuclear
Engineering Technology, vol. 47, pp. 924-933, 2015.

[5] M. A. Rahman, M. O. Raruk, Shanfiqul, "Application of anion exchange resin for the separation of metal in Tert-butyl-Alcohol waterformic acid medium", Journal Science vol. 60 no.1, pp. 15-20, 2012.

[6] American Standard Test Methods, "Standard test methods for the ion exchange separation of uranium and plutonium prior to isotopic analysis," ASTM C1411-01 vol. 12 no.1, 2000.

[7] A. B. Ginting, D. Anggraini, "Metode pengendapan dan penukar kation untuk pemisahan cesium dalam bahan bakar $\mathrm{U}_{3} \mathrm{Si}_{2}-\mathrm{Al}$ ", Jurnal IImiah Daur Bahan Bakar Nuklir Urania, vol. 22 no. 2, hal. 65-132, 2016.

[8] Boybul, Yanlinastuti, S. Indaryati, I. Haryati, A. Nugroho, "Penentuan Kandungan Isotop ${ }^{235} \mathrm{U}$ Dalam PEB $\mathrm{U}_{3} \mathrm{Si}_{2}-\mathrm{Al} \quad \mathrm{T}_{\mathrm{MU}}{ }_{2}, 96 \mathrm{gU} / \mathrm{cm}^{3}$ Untuk Perhitungan Burn Up", Jurnal IImiah Daur Bahan Bakar Nuklir Urania, vol. 21 no. 3, hal. 141-150, 2015.

[9] A. Bharadwaj and S. D. Bharadwaj, "Anion exchange separation of some lanthanida ions with uranium (VI) using nitrate complexing media", International Journal of Chemical Sciences, vol.1 no.1, pp. 67-72,2003.

[10] V.Koprda, M. Fojtik, M. Szilaurova, "Anion exchange in mixed solvent system, study of the equilibrium distribution", Research Institute of Industrial Hygiene and Occupational Diseases, 1972.

[11] Yanlinastuti, Boybul, A. B. Ginting, D. Anggraini, "Pengaruh parameter proses elektrodeposisi terhadap penentuan berat isotop ${ }^{235} \mathrm{U}$ dalam PEB $\cup_{3} \mathrm{Si}_{2} / \mathrm{Al}$ pasca iradiasi", Jurnal Ilmiah Daur Bahan Bakar Nuklir Urania, vol. 22 no. 2, 2016.

[12] S. Usuda, "Studies on rapid ion exchange separation of 
transplutonium elements with mineral acid-metanol mixed media", Technical Report, JAERI 1315,1989.

[13] K. Sawada, Y. Enokida, M. Kamiya, T. Koyama, K. Aoki, "Distribution coefficient of $\mathrm{U}(\mathrm{VI})$, nitric acid and FP elements in extraction from concentrated aqeous solution of nitrates by $30 \%$ Tri-n Butylphosphate solution", Journal of Nuclear Science and Technology, vol 46 no 1, 2009. 